\title{
Edmond Picard - Léon Cladel, Lettres de France et de Belgique (1881-1889)
}

\section{Ida Merello}

\section{Q OpenEdition}

1 Journals

\section{Edizione digitale}

URL: http://journals.openedition.org/studifrancesi/6400

DOI: $10.4000 /$ studifrancesi.6400

ISSN: 2421-5856

\section{Editore}

Rosenberg \& Sellier

\section{Edizione cartacea}

Data di pubblicazione: 1 novembre 2010

Paginazione: 581

ISSN: 0039-2944

\section{Notizia bibliografica digitale}

Ida Merello, «Edmond Picard - Léon Cladel, Lettres de France et de Belgique (1887-1889)», Studi Francesi [Online], 162 (LIV | III) | 2010, online dal 30 novembre 2015, consultato il 09 janvier 2021. URL: http:// journals.openedition.org/studifrancesi/6400 ; DOI: https://doi.org/10.4000/studifrancesi.6400

Questo documento è stato generato automaticamente il 9 janvier 2021.

\section{(c) $(1) \&$}

Studi Francesi è distribuita con Licenza Creative Commons Attribuzione - Non commerciale - Non opere derivate 4.0 Internazionale. 


\section{Edmond Picard - Léon Cladel, Lettres de France et de Belgique (1881-1889)}

Ida Merello 


\section{NOTIZIA}

EDMOND PICARD - LÉON CLADEL, Lettres de France et de Belgique (1881-1889). Édition présentée, établie et annotée par Fabrice DE KERCKHOVE, Bruxelles, AML Éditions, 2009, pp. 342.

Il volume raccoglie otto anni di corrispondenza in larga parte inedita tra il direttore dell' «Art moderne» e lo scrittore Léon Cladel, la relazione fatta da Picard sul primo soggiorno di Cladel in Belgio, le lettere dal Belgio che Picard pubblicò sui giornali «La Justice» di Clemenceau e «L'événement» di Edmond Magnier, e infine il pamphlet anonimo (attribuito a Léopold Pels) intitolato Coups d'encensoir! À Edmond Picard. Questo ricco materiale è corredato da un'ampia postfazione che, attraverso l'analisi del corpus pubblicato, ripercorre il movimento delle idee estetiche e politiche nel decennio 1880-1890. L'A. mette molto bene in evidenza il ruolo significativo che cladel svolse in Belgio, grazie all'appoggio di Picard, diventando il promotore di un naturalismo parnassiano che alla rappresentazione delle malattie della società, con intenti politici, scientifici ed etici, opponeva una sorta di epopea del popolo. La sua forte personalità suscitò l'entusiasmo delle giovani generazioni belghe, in particolare di claude Lemonnier e di Verhaeren, che abbracciò inizialmente le sue teorie estetiche. L'A. definisce con precisione l'evoluzione ideologica della rivista di Picard, che accompagna l'avanguardia dal primitivo naturalismo socialisteggiante al simbolismo degli anni '90, indugiando anche su quegli aspetti nazionalistici che investivano non solo le scelte linguistiche - le varianti localistiche del francese - ma anche gli atteggiamenti razzisti, antisemiti e misogini, in nome di un culto della cultura virile pericolosamente vicino alle posizioni della destra. Il carteggio Picard-Cladel diventa così pretesto per uno sguardo ravvicinato su uno dei momenti più complessi della storia letteraria e per una sua riscrittura sulla base di documenti di prima mano. 